\title{
Altered Responsiveness to Cocaine and Increased Immobility in the Forced Swim Test Associated with Elevated cAMP Response Element-Binding Protein Expression in Nucleus Accumbens
}

\author{
Andrea M. Pliakas, ${ }^{1}$ Richard R. Carlson, ${ }^{1}$ Rachael L. Neve, ${ }^{1}$ Christine Konradi, ${ }^{1}$ Eric J. Nestler, ${ }^{2}$ and \\ William A. Carlezon Jr ${ }^{1}$ \\ ${ }^{1}$ Department of Psychiatry, Harvard Medical School, McLean Hospital, Belmont, Massachusetts 02478, and \\ 2Department of Psychiatry, The University of Texas Southwestern Medical Center, Dallas, Texas 75390-9070
}

Drugs of abuse regulate the transcription factor cAMP response element-binding protein (CREB) in striatal regions, including the nucleus accumbens (NAc). To explore how regulation of CREB in the NAc affects behavior, we used herpes simplex virus (HSV) vectors to elevate CREB expression in this region or to overexpress a dominant-negative mutant CREB (mCREB) that blocks CREB function. Rats treated with HSVmCREB in place conditioning studies spent more time in environments associated with cocaine, indicating increased cocaine reward. Conversely, rats treated with HSV-CREB spent less time in cocaine-associated environments, indicating increased cocaine aversion. Studies in which drug-environment pairings were varied to coincide with either the early or late effects of cocaine suggest that CREB-associated place aversions reflect increased cocaine withdrawal. Because cocaine withdrawal can be accompanied by symptoms of depression, we examined how altered CREB function in the NAc affects behavior in the forced swim test (FST). Elevated CREB expression increased immobility in the FST, an effect that is opposite to that caused by standard antidepressants and is consistent with a link between CREB and dysphoria. Conversely, overexpression of mCREB decreased immobility, an effect similar to that caused by antidepressants. Moreover, the $\kappa$ opioid receptor antagonist nor-Binaltorphimine decreased immobility in HSV-CREB- and HSV-mCREB-treated rats, suggesting that CREB-mediated induction of dynorphin (an endogenous $\kappa$ receptor ligand) contributes to immobility behavior in the FST. Exposure to the FST itself dramatically increased CREB function in the NAc. These findings raise the possibility that CREBmediated transcription within the NAc regulates dysphoric states.

Key words: CREB; nucleus accumbens; cocaine; reward; aversion; depression; $\kappa$ opioid receptor; rat
The mesolimbic dopamine system, which originates in the ventral tegmental area and projects to the nucleus accumbens (NAc), is a substrate for the rewarding effects of drugs of abuse (Kreek and Koob, 1998; Wise, 1998). Drugs of abuse cause complex neuroadaptations in this system (Nestler, 2001), some of which are associated with altered drug sensitivity. One neuroadaptation involves cAMP response element-binding protein (CREB), a transcription factor that is activated in striatal regions (including the NAc) by psychostimulants (Cole et al., 1995; Turgeon et al., 1997). CREB in the NAc appears to regulate the rewarding and aversive effects of cocaine. Stimulation of cAMP-dependent protein kinase A (PKA), which activates CREB, in the NAc decreases cocaine reward (Self et al., 1998). Similarly, elevation of CREB expression in the NAc decreases cocaine reward and makes low doses of the drug aversive (Carlezon et al., 1998). Conversely, blockade of PKA activity or overexpression of a dominant-negative CREB [mutant CREB (mCREB), which functions as a CREB antagonist] (Gonzalez and Montminy, 1989) in the NAc each increase cocaine reward (Carlezon et al., 1998; Self

Received March 5, 2001; revised July 6, 2001; accepted July 6, 2001.

This research was supported by a Young Investigator Award from the National Alliance for Research on Schizophrenia and Depression and a donation by John A. Kaneb (W.A.C.). Support was also provided by the National Institute of Mental Health (W.A.C., E.J.N.) and by the National Institute on Drug Abuse (E.J.N., C.K.). Correspondence should be addressed to Dr. Bill Carlezon, Department of Psychiatry, McLean Hospital, MRC 217, 115 Mill Street, Belmont, MA 02478. E-mail: carlezon@mclean.harvard.edu.

Copyright (C) 2001 Society for Neuroscience $0270-6474 / 01 / 217397-07 \$ 15.00 / 0$ et al., 1998). These findings suggest that CREB activation in the NAc counteracts drug reward and increases drug aversion.

The effects of CREB in the NAc may involve dynorphin, a neuropeptide associated with decreased function of the mesolimbic dopamine system (Di Chiara and Imperato, 1988; Spanagel et al., 1990) and dysphoria (Pfeiffer et al., 1986; Bals-Kubik et al., 1993). Psychostimulants increase dynorphin expression in the NAc and dorsal striatum (STR) (Hurd et al., 1992; Daunais et al., 1993; Spangler et al., 1993), an effect that is consistent with their ability to activate CREB in these regions. In addition, CREB regulates dynorphin gene expression in vitro (Cole et al., 1995; Turgeon et al., 1997). Viral-mediated elevations of CREB in the NAc increase dynorphin mRNA, whereas overexpression of mCREB diminishes dynorphin mRNA (Carlezon et al., 1998). Blockade of $\kappa$ opioid receptors, on which dynorphin acts (Chavkin et al., 1982), prevents the aversive effects of elevated CREB expression in the NAc (Carlezon et al., 1998). These findings not only strengthen associations between CREB and dynorphin in the NAc, but considering that $\kappa$ agonists are aversive in humans (Pfeiffer et al., 1986) and rats (Bals-Kubik et al., 1993), they suggest that CREB activation in this region regulates aversive (dysphoric) states.

One goal of the present studies was to examine the mechanisms by which elevated CREB expression in the NAc causes aversive responses to cocaine. Using viral vector-mediated gene transfer (Carlezon et al., 2000b), we explored the possibility that this effect of CREB reflects increased cocaine withdrawal. In place- 
conditioning studies, we manipulated drug-environment pairings to coincide with peak cocaine effects (promoting place preferences) or with the offset of drug actions (promoting place aversions). Because cocaine withdrawal is accompanied by signs of depression in humans (Gawin et al., 1989) and in rats (Markou et al., 1992), we also examined how CREB function within the NAc affects behavior in the forced swim test (FST) (Porsolt et al., 1977), an assay used in depression research.

\section{MATERIALS AND METHODS}

Rats and surgery. A total of 244 male Sprague Dawley rats (300-350 gm) (Charles River, Boston MA) were used. Rats were housed in hanging wire cages for place-conditioning studies (conducted at Yale University, New Haven, CT) and in clear polypropylene boxes containing wood shavings for forced swimming studies (conducted at McLean Hospital). Rats were maintained on a $12 \mathrm{hr}$ light/dark (7:00 A.M. to 7:00 P.M.) cycle with access to food and water except during testing. Experiments were conducted in accordance with the 1996 National Institutes of Health Guide for the Care and Use of Laboratory Animals.

Viral vectors. cDNAs for CREB and mCREB (obtained from M. E. Greenberg, Harvard University, Boston, MA) and LacZ were inserted into the herpes simplex virus (HSV) amplicon HSV-PrpUC and packaged into virus using the helper $5 d l 1.2$, as described previously (Neve et al., 1997). Virus was purified on a sucrose gradient, pelleted, and resuspended in $10 \%$ sucrose. The titer of the vector stocks was $\sim 4.0 \times 10^{7}$ infectious units/ml. For each study, aliquots from the same batches of the viral vectors were used. Transgene expression caused by these vectors is maximal 3-4 d after treatment and minimal by day 10 (Carlezon et al., 1998).

Place conditioning. Sixty-five rats were used in place-conditioning studies, which occurred in a three compartment apparatus (Carlezon et al., 1998). During screening (day 0) rats were placed in the small $(12 \times 18 \times$ $33 \mathrm{~cm}$ ) central compartment and were allowed to explore the entire apparatus for $30 \mathrm{~min}$. The compartments differed in floor texture, wall striping, and lighting. Rats that did not show a baseline preference $(\geq 18$ $\mathrm{min})$ for a compartment were anesthetized $(65 \mathrm{mg} / \mathrm{kg}$ sodium pentobarbital, i.p.) and given atropine $(0.25 \mathrm{mg}$, s.c.) to minimize bronchial secretions. Each rat received bilateral microinjections $(2.0 \mu \mathrm{l}$ per side) of HSV-CREB $(n=21)$, HSV-mCREB $(n=20)$, or vehicle (10\% sucrose; $n=24)$ aimed at the NAc shell [relative to bregma: anteroposterior (AP), $+1.7 \mathrm{~mm}$; lateral (Lat), \pm 2.3 ; and dorsoventral (DV), $6.8 \mathrm{~mm}$ below dura] (Paxinos and Watson, 1997). The NAc shell was targeted specifically because we have shown previously that this region is critical for the rewarding effects of cocaine (Carlezon et al., 1995) and other stimulants (Carlezon and Wise, 1996), and also because we have shown previously that the effects of the CREB vectors on cocaine reward and aversion are more pronounced in the shell than in the NAc core (Carlezon et al., 1998). Injections were made over 10 min using a 26 gauge Hamilton syringe angled at $10^{\circ}$ from the midline. After $2 \mathrm{~d}$ of recovery, conditioning trials (two per day) were given on 2 consecutive days (days 3 and 4 ). On the first conditioning trial of each day, rats received saline $(1 \mathrm{ml} / \mathrm{kg}$, i.p. $)$ and were confined to one of the large $(24 \times 18 \times 33 \mathrm{~cm})$ side compartments of the apparatus. After $3 \mathrm{hr}$, rats received cocaine $(1.25 \mathrm{mg} / \mathrm{kg}$, i.p.; National Institute on Drug Abuse) and were confined to the other side compartment. Each rat was assigned to one of the three types of conditioning sessions that were used: a $1 \mathrm{hr}$ pairing session, in which the rats received cocaine (or vehicle) and were placed immediately into the apparatus for $1 \mathrm{hr}$; a 15 min pairing session, in which the rats were injected and placed immediately into the apparatus for $15 \mathrm{~min}$; or a delayed pairing session, in which the rats were injected and placed in the apparatus after a 15 min delay for $1 \mathrm{hr}$. On the final day (day 5), rats were again allowed to freely explore the entire apparatus for $30 \mathrm{~min}$. Place-conditioning data were analyzed using a two-way (treatment $\times$ type of pairing) ANOVA, followed by post hoc comparisons with Fisher's $t$ tests (two-tailed).

FST. A total of 117 rats were used in experiments involving forced swimming. The FST is a $2 \mathrm{~d}$ procedure in which rats swim under conditions in which escape is not possible. On the first day, the rats are forced to swim for $15 \mathrm{~min}$. The rats initially struggle to escape from the water, but eventually they adopt a posture of immobility in which they make only the movements necessary to keep their heads above water. When the rats are retested $24 \mathrm{hr}$ later, immobility is increased. Treatment with standard antidepressant drugs within the $24 \mathrm{hr}$ between the first exposure to forced swimming and retesting can block facilitated immobility, an effect associated with antidepressant efficacy in humans (Porsolt et al., 1977; Detke et al., 1995).

In one experiment, 47 rats were used to examine the effects of CREB function in the NAc on the development of facilitated immobility in the FST. Rats received bilateral microinjections of $\operatorname{HSV}-\mathrm{CREB}(n=9)$, HSV-mCREB $(n=10)$, or HSV-LacZ $(n=11)$ aimed at the NAc shell or received sham surgery $(n=17)$. These rats were first exposed to forced swimming $3 \mathrm{~d}$ after gene transfer, when transgene expression is maximal (Carlezon et al., 1998). Retesting was conducted 24 hr later (day 4). Data from the retest session were analyzed using a one-way ANOVA followed by Fisher's $t$ tests.

In a second experiment, 28 rats were used to examine whether the effects of gene transfer were transient. Rats received bilateral microinjections of HSV-CREB $(n=8)$ or HSV-mCREB $(n=8)$ aimed at the NAc shell or received sham surgery $(n=12)$. These rats were first exposed to forced swimming $10 \mathrm{~d}$ after gene transfer, when transgene expression has waned (Carlezon et al., 1998). Retesting was conducted 24 hr later (day 11). Data from the retest session were analyzed using a one-way ANOVA followed by Fisher's $t$ tests.

In a third experiment, 42 rats were used to examine the effects of the $\kappa$ opioid receptor antagonist nor-Binaltorphimine (norBNI) (Research Biochemicals, Natick, MA) on facilitated immobility in the FST. Intracerebroventricular microinjections (relative to bregma, AP, -0.3 ; Lat, +1.2 ; and DV, $4.0 \mathrm{~mm}$ below dura) of norBNI $(5.0$ or $20 \mu \mathrm{g})$ were administered in $2.0 \mu \mathrm{l}$ of deionized water over $10 \mathrm{~min}$ immediately before gene transfer (or sham surgery). At the dosages used, norBNI produces a $\kappa$ receptor-specific blockade in rats (Jones and Holtzman, 1992) for $>3$ weeks (Spanagel and Shippenberg, 1993). Rats then received bilateral microinjections of HSV-CREB $(n=12)$ or HSV$\operatorname{mCREB}(n=12)$ aimed at the NAc shell or received sham surgery $(n=$ 18). These rats were exposed to forced swimming on day 3 and were retested on day 4. Data were analyzed using a two-way ANOVA (vector treatment $\times$ norBNI dosage) followed by Fisher's $t$ tests.

For all FST studies, on the first day the rats were placed in clear Plexiglas cylinders $(65 \mathrm{~cm}$ tall $\times 25 \mathrm{~cm}$ diameter $)$ filled to $48 \mathrm{~cm}$ with $25^{\circ} \mathrm{C}$ water. After $15 \mathrm{~min}$ of forced swimming, the rats were removed from the water, dried with towels, and placed in a warmed enclosure for $30 \mathrm{~min}$. The cylinders were emptied and cleaned between rats. At $24 \mathrm{hr}$ after the forced swim, rats were retested for $5 \mathrm{~min}$ under identical conditions. The FST data presented in the present report were collected during retest sessions, which were videotaped from the side of the cylinders.

Videotapes were scored by raters unaware of the treatment condition. Latency to become immobile was defined as the time at which the rat first initiated a stationary posture that did not reflect attempts to escape from the water. In this characteristic posture, the forelimbs are motionless and tucked toward the body. To qualify as immobility, this posture had to be clearly visible and maintained for $\geq 2.0 \mathrm{sec}$. In our experience, this method of scoring has the highest inter-rater reliability $(r=0.99)$ of the many methods that can be used to score the FST, and it is sensitive to standard antidepressants such as desipramine and fluoxetine (data not shown).

Locomotor activity. Thirty-four rats were used to examine how the gene transfer treatments affect locomotor activity. Rats received HSVCREB $(n=7)$, HSV-mCREB $(n=7)$, or HSV-LacZ $(n=6)$ aimed at the NAc shell or received sham surgery $(n=14)$. Three days after surgery, rats underwent day 1 of the FST. At $24 \mathrm{hr}$ after forced swimming, the rats were placed for $1 \mathrm{hr}$ in automated, $68 \times 21 \times 21 \mathrm{~cm}$ activity chambers (Med Associates, St. Albans, VT). Data were analyzed using separate one-way ANOVAs followed by Fisher's $t$ tests.

Sixteen rats were used to examine how treatment with norBNI affects locomotor activity. Three days after intracerebroventricular microinjections of norBNI $(20 \mu \mathrm{g})$ or vehicle (deionized water), rats underwent day 1 of the FST. At $24 \mathrm{hr}$ after forced swimming, the rats were placed for 1 $\mathrm{hr}$ in the activity chambers. Data were analyzed using a Student's $t$ test.

Transgene detection. Immediately after the final test sessions, rats that received gene transfer and/or intracerebroventricular microinjections of norBNI were overdosed with pentobarbital $(130 \mathrm{mg} / \mathrm{kg}$, i.p.) and perfused with $0.9 \%$ saline followed by $4 \%$ paraformaldehyde. Brains were kept overnight in $20 \%$ glycerol before slicing $(40 \mu \mathrm{m})$. Transgene expression (CREB, mCREB, and LacZ) and/or injection placements were verified by histological analyses (Carlezon et al., 1998). To detect $\beta$-galactosidase, a $0.2 \mathrm{mg} / \mathrm{ml}$ 5-bromo-4-chloro-3-indolyl $\beta$-Dgalactopyranoside (Fisher Scientific, Houston, TX) solution was used; to 


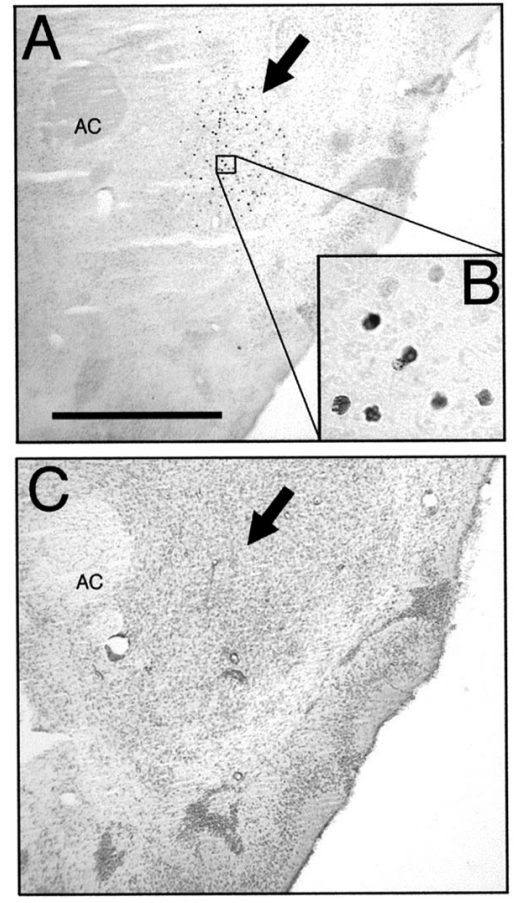

Figure 1. Histological examination of the NAc after gene transfer. $A$, Expression of CREB $5 \mathrm{~d}$ after microinjection of HSV-CREB into the left NAc shell (40× magnification). The arrow indicates the injection site. Scale bar, $1 \mathrm{~mm}$. $B$, Higher magnification $(200 \times)$ of the injection site in $A$, confirming nuclear localization of CREB expression. Expression of mCREB (data not shown) is indistinguishable from that of CREB. $C$, An adjacent, Nissl-stained slice from the same brain. $A C$, Anterior commissure. The arrow indicates the injection site.

detect CREB and mCREB (Carlezon et al., 1998), a CREB antibody (1:1000; Upstate Biotechnology, Lake Placid, NY) solution containing $1 \%$ bovine serum albumin-2\% normal goat serum was used. Immunohistochemical conditions were designed to minimize detection of endogenous CREB, which is expressed ubiquitously in brain. Data from rats with placements outside the intended regions were excluded from analyses.

Protein immunoblotting. Twelve rats were used to examine how forced swimming affects CREB phosphorylation in the NAc shell and dorsal STR. Some rats $(n=6)$ underwent the first day of the FST, whereas control rats $(n=6)$ were brought to the test room but were not placed in the water. Rats were decapitated 10 min after forced swimming, and a tissue slicer (Stoelting, Kiel, W I) was used to make $1.0 \mathrm{~mm}$ coronal brain slices containing the central aspects of the NAc shell and STR $(\sim 1.2-2.2$ anterior to bregma). Bilateral 15 gauge punches of the NAc shell and STR were obtained and placed on dry ice within $150 \mathrm{sec}$ of decapitation.

Published methods for detection of phosphorylated CREB (P-CREB) were used (Rajadhyaksha et al., 1999). Tissue was homogenized in buffer (in mM: 10 Tris, $\mathrm{pH} 7.5,50 \mathrm{NaF}, 2 \mathrm{Na}_{3} \mathrm{VO}_{4}, 1$ EDTA, and 1 EGTA) and diluted to $4 \mu \mathrm{g}$ of protein per microliter. The tissue solution was diluted 1:1 with $2 \times$ Laemmli buffer (in $20 \mathrm{ml}: 100 \mathrm{~mm}$ Tris, $\mathrm{pH}$ 6.8, $1.2 \mathrm{gm}$ of SDS, $4.0 \mathrm{ml}$ of glycerol, $0.2 \mathrm{mg}$ of bromphenol blue, and $620 \mathrm{mg}$ of DTT), heated to $80^{\circ} \mathrm{C}$ for $5 \mathrm{~min}$, and loaded $(20 \mu \mathrm{g}$ of protein) onto $12 \%$ polyacrylamide gels. After electrophoretic transfer, the polyvinylidene membranes were incubated with P-CREB antibody (1:2000; Upstate Biotechnology) overnight at $4^{\circ} \mathrm{C}$. After incubation in secondary antibody (HRP-conjugated goat antibody to rabbit IgG, 1:10,000; Vector Laboratories, Burlingame, CA) for $2 \mathrm{hr}$, immunoreactivity was visualized with chemiluminescence (NEN, Boston, MA) using a Kodak Image Station 440 (Eastman Kodak, Rochester, NY). Blots were quantified by image analysis (Kodak Digital Science 1D), and data were expressed as the ratio of P-CREB expression in pairs of rats exposed to swimming and those not exposed to swimming for each region. A Student's $t$ test was used to examine statistical significance.

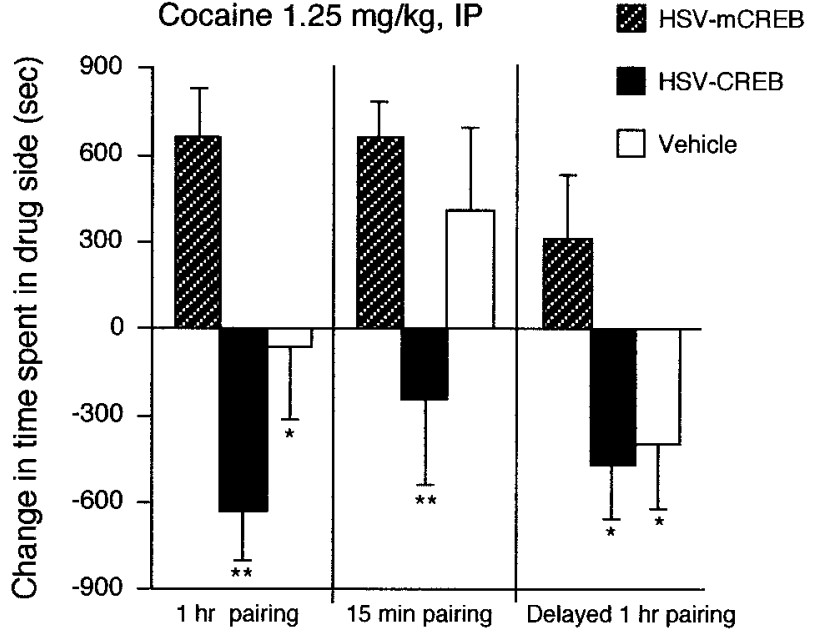

Figure 2. Effect of HSV treatments on cocaine $(1.25 \mathrm{mg} / \mathrm{kg}$, i.p.) place conditioning. Data are expressed as the change in time spent in cocaineassociated environments (mean \pm SEM; 8-11 rats per group). In $1 \mathrm{hr}$ conditioning sessions (left), rats given intra-NAc (shell) microinjections of HSV-mCREB spent more time in cocaine-associated environments than rats given similar microinjections of vehicle (10\% sucrose) or HSVCREB. Shortening the conditioning sessions to $15 \mathrm{~min}$ (middle) eliminated differences between rats in the HSV-mCREB and vehicle groups only. Differences persisted when $1 \mathrm{hr}$ conditioning sessions were delayed by $15 \min (r i g h t) .{ }^{*} p<0.05,{ }^{*} p<0.01$ compared with HSV-mCREB groups; Fisher's $t$ test.

\section{RESULTS}

\section{Viral vector-mediated gene transfer}

As reported previously (Carlezon et al., 1998), microinjections of HSV-CREB, HSV-mCREB, or HSV-LacZ produced 2000 transgene-labeled cells in each NAc $3 \mathrm{~d}$ after gene transfer. This number was lower when the tissue was examined at the completion of behavioral testing, $5 \mathrm{~d}$ (Fig. $1 A$ ) or $11 \mathrm{~d}$ (data not shown) after gene transfer, indicating the transient nature of transgene expression caused by these HSV vectors. Transgene expression was limited to an area of $\sim 1.5 \mathrm{~mm}$ in diameter (Carlezon et al., 1997, 1998, 2000a; Kelz et al., 1999), and it occurred only in neurons (our unpublished observations), consistent with the fact that HSV is known to be neurotropic (Carlezon et al., 2000b). CREB and mCREB immunoreactivity were indistinguishable (Carlezon et al., 1998) and were restricted to the cell nucleus, where the transcription factor is localized under normal conditions (Fig. 1B). The vectors caused minimal damage (Fig. 1C), which was indistinguishable from that caused by microinjections of vehicle (10\% sucrose).

\section{Cocaine place conditioning}

In the place-conditioning assay, rats tend to approach environments associated with rewarding drug effects and avoid environments associated with aversive drug effects or drug withdrawal (Carr et al., 1989). At a threshold dose of cocaine $(1.25 \mathrm{mg} / \mathrm{kg}$, i.p.), changes in the time spent in cocaine-associated environments (mean $\pm \mathrm{SEM}$; six to nine rats per group) depended on viral vector treatment $\left(F_{(2,56)}=3.38 ; p<0.05\right)$ and conditioning procedure $\left(F_{(2,56)}=14.6 ; p<0.01\right)$. In $1 \mathrm{hr}$ conditioning sessions (Fig. 2, left), rats given microinjections of HSV-mCREB into the NAc shell spent more time in cocaine-associated environments than rats given similar microinjections of sucrose (vehicle) or HSV-CREB. We have demonstrated previously that there are no differences in place conditioning among rats that received micro- 

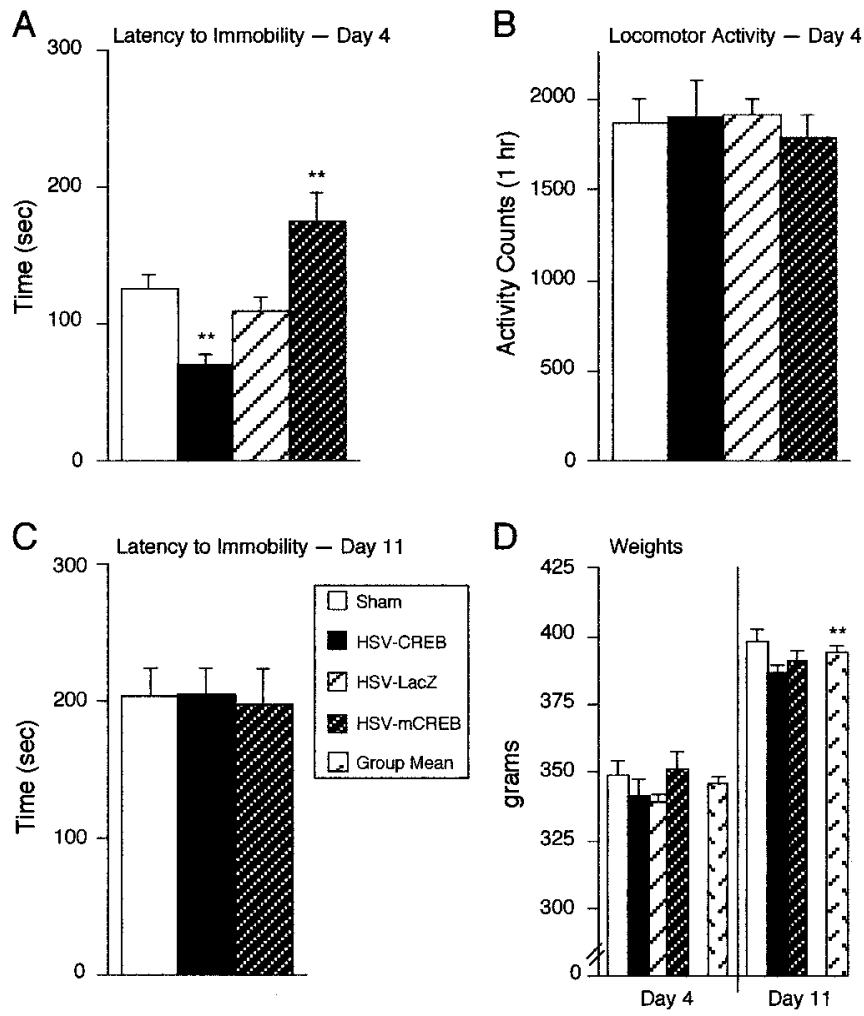

Figure 3. Effect of HSV treatments on the FST. A, Latencies to become immobile depended on viral vector treatment when transgene expression was maximal (days 3 and 4). Latencies were decreased in rats treated with HSV-CREB and increased in rats given HSV-mCREB. HSV-LacZ had no effect. Data are expressed as latencies (mean \pm SEM, in seconds) during the 5 min test on day 4 . There were no group differences when activity rather than swimming was quantified during testing $(B)$ or when the FST was conducted after transgene expression had diminished $(C)$ (days 10 and 11). Data in $C$ are expressed as latencies during the $5 \mathrm{~min}$ test on day 11. $D$, Gene transfer did not affect rat weights, but rats tested on day 11 weighed more than rats tested on day $4 .{ }^{* *} p<0.01$ compared with sham-treated rats; Fisher's $t$ test.

injections of vehicle (10\% sucrose), a control virus (HSV-LacZ, expressing $\beta$-galactosidase), or sham surgery (no microinjections) (Carlezon et al., 1997, 1998, 2000a; Kelz et al., 1999). Shortening the conditioning sessions to $15 \mathrm{~min}$ (Fig. 2, middle) increased the amount of time that rats given microinjections of sucrose spent in cocaine-associated environments, suggesting peak cocaine reward during this period. This conditioning regimen did not increase the amount of time that rats given HSV-mCREB spent in cocaine-associated environments, which is consistent with previous observations that there is an upper limit to the magnitude of place preferences that can be observed in this model (Carr et al., 1989; Carlezon et al., 1998). This shortened regimen eliminated the significant differences between rats given HSV-mCREB and those given sucrose, whereas rats given HSV-CREB still avoided cocaine-associated environments. Conditioning sessions delayed by $15 \mathrm{~min}$ (Fig. 2, right) tended to decrease cocaine place preferences in rats given HSV-mCREB or sucrose, which further isolates peak cocaine reward to early in the conditioning sessions. Indeed, cocaine appeared aversive in rats given intra-NAc microinjections of sucrose. This delayed regimen did not further decrease the amount of time that rats given HSV-CREB spent in cocaine-associated environments, suggesting that there is an upper limit to the magnitude of place aversions in this model.
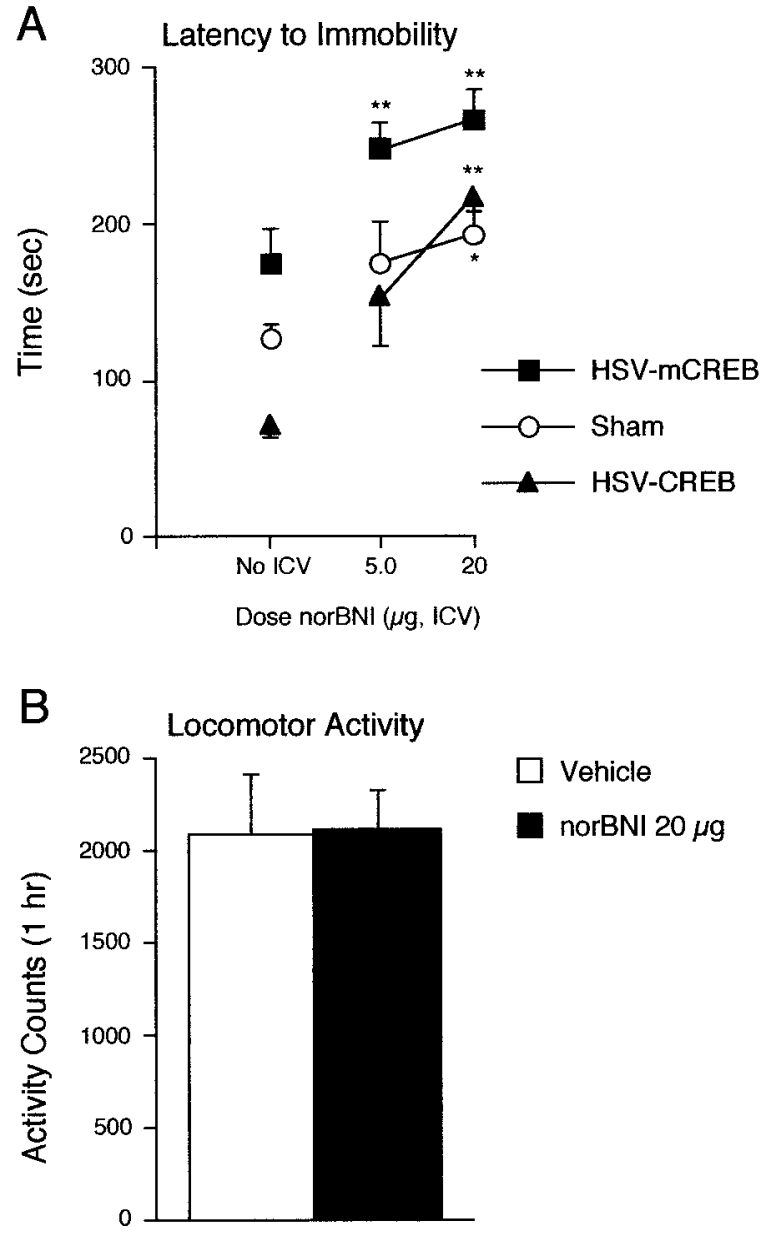

Figure 4. A, Effect of norBNI (5.0 or $20 \mu \mathrm{g}$, i.c.v.) on the FST. Treatment with norBNI dose-dependently increased latencies to become immobile (mean $\pm \mathrm{SEM}$ ) in each group. ${ }^{*} p<0.05,{ }^{* *} p<0.01$ (Fisher's $t$ tests), compared with no intracerebroventricular for each treatment. $B$, There were no effects of norBNI $(20 \mu \mathrm{g}$, i.c.v. $)$ when locomotor activity rather than swimming was quantified during testing.

\section{Effects of CREB in the FST}

In the FST, the amount of time that a rat continues to struggle in the water (latency to become immobile) during the second exposure to forced swimming is predictive of antidepressant action. When the FST studies were conducted at times of maximal transgene expression (days 3 and 4 after viral vector-mediated gene transfer), latencies to become immobile on the test day depended on viral vector treatment $\left(F_{(3,43)}=8.83 ; p<0.01\right)$ (Fig. $3 A)$. Latencies to become immobile in rats given microinjections of HSV-CREB into the NAc shell were significantly shorter $(p<$ 0.01 ; Fisher's $t$ tests) than those of sham-treated rats, an effect opposite to that caused by standard antidepressants (data not shown). Conversely, the latencies of rats treated with HSVmCREB were significantly longer $(p<0.01)$ than those of shamtreated rats, an effect similar to that caused by standard antidepressants (Porsolt et al., 1977). Treatment with HSV-LacZ had no effect on latencies to become immobile. There were no group differences when locomotion rather than swimming was quantified in activity chambers on the test day (Fig. $3 B$ ), confirming that antidepressant-like effects in this assay are not related to treatment-induced changes in locomotor activity.

When the FST studies were conducted after transgene expres- 
sion had diminished (days 10 and 11), there were no group differences in latencies to become immobile (Fig. $3 C$ ), indicating that the behavioral effects of the HSV vectors are transient and have a time course that parallels transgene expression. However, latencies to become immobile were generally higher at these later time points. This effect was likely attributable to the significant increases $(\sim 50 \mathrm{gm})$ in the weights of the rats during the additional week between surgery and the FST (Fig. 3D); gene transfer did not affect rat weights, but rats tested on day 11 weighed more than rats tested on day $4\left(t_{(73)}=10.6 ; p<0.01\right)$. We have seen similar effects in unoperated rats as weights approach $400 \mathrm{gm}$ (data not shown), which would appear to rule out the possibility that the increased surgical recovery time contributes to increased latencies to become immobile.

Treatment with norBNI dose-dependently increased latencies to become immobile (Fig. $4 A$ ) in sham-, HSV-CREB-, and HSVmCREB-treated rats (main effect of dose: $F_{(2,69)}=14.1 ; p<0.01$ ) (main effect of vector: $F_{(2,69)}=11.7 ; p<0.01$ ), indicating an antidepressant-like effect. Treatment with $20 \mu \mathrm{g}$ of norBNI had no effect on locomotion when locomotion rather than swimming was quantified in activity chambers on the test day (Fig. 4B).

\section{Effect of forced swimming on P-CREB}

Levels of P-CREB (the activated form of CREB) were analyzed in tissue punches obtained from the NAc shell or dorsal striatum [caudate putamen (CPU)] (Fig. 5A). Forced swimming caused significant increases in P-CREB within the NAc shell $\left(t_{(10)}=\right.$ 2.48; $p<0.05$ ) but no change within the CPU (Fig. $5 B$ ).

\section{DISCUSSION}

\section{CREB in the NAc regulates signs of dysphoria}

These studies demonstrate that CREB activation in the NAc shell regulates cocaine reward and aversion. Rats with viral-mediated elevations of CREB in the NAc shell avoided cocaine-associated environments, suggesting that increased CREB in this region is associated with drug aversion or dysphoria. We have shown previously that viral-mediated elevations of CREB in the NAc shell elevate local dynorphin mRNA, confirming increased CREB-mediated gene transcription (Carlezon et al., 1998). The present data are consistent with work demonstrating that activation of PKA in the NAc with microinjections of $S_{\mathrm{p}}$-cAMPs, which increases CREB phosphorylation, causes shifts in intravenous cocaine self-administration dose-response functions that indicate less cocaine reward (or more cocaine aversion) (Self et al., 1998). Conversely, overexpression of mCREB (dominantnegative $\mathrm{CREB}$ ) in the NAc shell increases cocaine place preferences, suggesting that decreased CREB in this region is associated with increased cocaine reward or decreased cocaine aversion. Overexpression of $\mathrm{mCREB}$ in the NAc shell decreases dynorphin mRNA, confirming antagonism of CREB-mediated gene transcription (Carlezon et al., 1998). These data are consistent with findings that direct inhibition of PKA in the NAc with microinjections of $R_{\mathrm{p}}$-cAMPs, which decreases CREB phosphorylation, causes shifts in cocaine self-administration dose-response functions that indicate more cocaine reward (or less cocaine aversion) (Self et al., 1998). Because elevation of CREB caused strong place aversions and overexpression of mCREB caused strong place preferences, these effects cannot be explained easily by general effects on learning. Together, our data indicate that CREB activation in the NAc shell is associated with decreased cocaine reward, increased cocaine aversion, or a combination of effects.
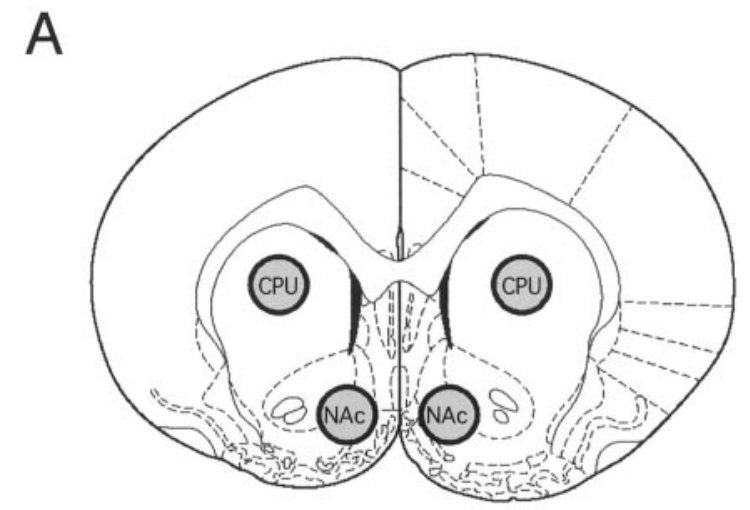

Bregma $1.60 \mathrm{~mm}$

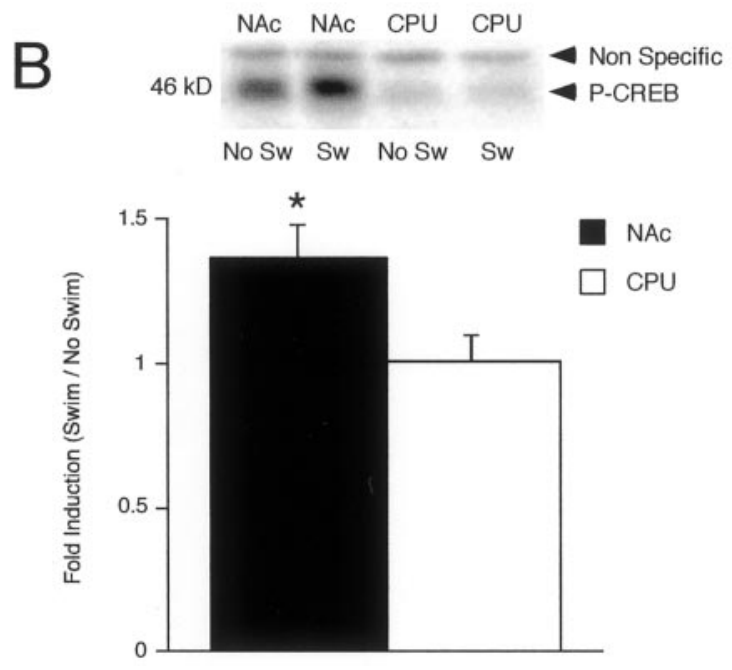

Figure 5. A, Locations from which NAc shell and CPU tissue punches were obtained (Paxinos and Watson, 1997). B, Western immunoblot of $\mathrm{P}-\mathrm{CREB}$ in the NAc shell and CPU after $15 \mathrm{~min}$ of forced swimming $(S w)$. Control rats did not undergo swimming $(N o S w)$. Forced swimming significantly increased P-CREB expression in the NAc but had no effect in the CPU. Data are expressed as the ratio (mean \pm SEM; 6 rats per group) of P-CREB expression in the $S w$ and No $S w$ groups for each region. * $p<$ 0.05 ; Student's $t$ test.

Studies in which we altered the timing of the cocaineconditioning sessions suggest that elevated CREB in the NAc shell causes cocaine place aversions because of effects specific to the late actions of the drug. When conditioning sessions began immediately after drug injection and lasted $1 \mathrm{hr}$ (our normal regimen), cocaine $(1.25 \mathrm{mg} / \mathrm{kg}$, i.p.) had no detectable rewarding or aversive effects in control rats given microinjections of sucrose (vehicle) into the NAc. When the conditioning sessions were shortened to $15 \mathrm{~min}$ immediately after cocaine, the drug began to establish place preferences in control rats, suggesting that cocaine reward is maximized when conditioning occurs during peak drug effects. Place preferences in control rats became qualitatively similar to those seen in rats treated with HSV-mCREB, whose place preferences likely did not increase because of ceiling effects (Carr et al., 1989). Even under these optimized conditions, however, rats treated with HSV-CREB in the NAc shell avoided cocaine-associated environments. When $1 \mathrm{hr}$ conditioning sessions were delayed by $15 \mathrm{~min}$, thereby promoting associations 
between drug-paired environments and the offset of cocaine actions (cocaine withdrawal), the drug began to establish place aversions in control rats. Place aversions in control rats became qualitatively similar to those seen in rats treated with HSVCREB, whose place aversions likely did not increase further because of floor effects. One possible explanation for these data are that the rewarding effects of $1.25 \mathrm{mg} / \mathrm{kg}$ cocaine are rapid, transient, and followed by drug-opposite aversive or dysphoric states (Solomon and Corbit, 1974; Koob and Le Moal, 2001) related to acute withdrawal. Thus in the delayed-conditioning protocol, rats likely associated the cocaine-paired environments only with dysphoria. There was little effect of delayedconditioning sessions in rats treated with HSV-mCREB, suggesting that blockade of CREB transcription minimizes late, aversive cocaine actions.

\section{CREB in the NAc regulates signs of depression}

In humans, cocaine withdrawal causes symptoms of dysphoria and depression (Gawin et al., 1989). In rats, cocaine withdrawal is associated with hypofunction of the mesolimbic system, as indicated by increased intracranial self-stimulation thresholds (Markou et al., 1992). In humans and rats, antidepressants can attenuate symptoms of cocaine withdrawal (Gawin et al., 1989; Markou et al., 1992), suggesting that the symptoms involve signs of depression. Accordingly, we used the FST, an assay used in depression research, to test rats with viral-mediated alterations in CREB function within the NAc shell. Within the first FST session, rats gradually become immobile, making only those movements necessary to keep their heads above water. With retesting, immobility is increased (facilitated). The FST assay identifies treatments that have antidepressant efficacy in humans; many types of antidepressants decrease immobility during retesting, including tricyclics (e.g., desipramine) and selective serotonin re-uptake inhibitors (e.g., fluoxetine) (Porsolt et al., 1977; Detke et al., 1995). Interestingly, viral-mediated elevations of CREB expression in the NAc shell decrease latencies to become immobile, an effect opposite to that caused by antidepressants. These findings are consistent with the notion that elevated CREB in the NAc causes symptoms of dysphoria or depression. Conversely, overexpression of $\mathrm{mCREB}$ in the NAc shell increases latencies to become immobile, an effect similar to that seen with standard antidepressants. Overexpression of $\beta$-galactosidase (encoded by HSV-LacZ) had no effect on latencies to become immobile, indicating that viral-mediated gene transfer and elevated protein expression per se have no effect. None of the vector treatments altered spontaneous locomotor activity. Together, these data suggest that CREB activation in the NAc shell is a molecular "trigger" for facilitated immobility in the FST.

\section{CREB-mediated signs of depression are regulated by $\kappa$ opioid receptors}

CREB regulates many genes (Shaywitz and Greenberg, 1999), including that for dynorphin (Cole et al., 1995; Turgeon et al., 1997), a neuropeptide that acts at $\kappa$ opioid receptors. Synthetic $\kappa$ agonists cause dysphoria in humans (Pfeiffer et al., 1986), and intra-NAc microinjections of these agents establish place aversions in rats (Bals-Kubik et al., 1993). We have shown previously that intracerebroventricular microinjections of the $\kappa$ antagonist norBNI block cocaine place aversions associated with elevated CREB expression in the NAc shell. In the present studies, norBNI also dose-dependently increased latencies to become immobile in rats that received HSV-CREB, as well as in rats that received HSV-mCREB or sham surgery, without affecting locomotor activity. These data suggest that dynorphin actions at $\kappa$ receptors are involved in the increased immobility seen in the FST. Considering that dynorphin mRNA in the NAc shell is increased by HSV-CREB and decreased (but not eliminated) by HSV-mCREB, these data suggest links between CREB, dynorphin, $\kappa$ receptors, and increased immobility in the FST. In addition, the fact that CREB-induced cocaine place aversions and CREB-induced facilitation of immobility in the FST are each blocked by norBNI suggests that these behaviors have a similar neurobiological basis. One possibility is that CREB-mediated increases in dynorphin within the NAc decrease local dopamine tone via actions at $\kappa$ receptors on the terminals of mesolimbic dopamine neurons (Di Chiara and Imperato, 1988; Spanagel et al., 1990), an effect associated with aversion (Shippenberg et al., 1991).

\section{Stress-induced activation of CREB in the NAC}

We found that exposure to forced swimming increased P-CREB in the NAc but not in the CPU, a region typically associated with motor activity. This suggests that CREB activation within the mesolimbic system after forced swimming is not a nonspecific (motoric) consequence of swimming but rather a specific effect reflecting stress or dysphoria. These findings suggest a mechanism that may normally contribute to behavioral adaptations in the FST. The first exposure to the FST dramatically increases CREB activity in the NAc, an effect that, when mimicked by viral-mediated elevations in CREB expression, triggers increased immobility. If CREB activation in the NAc shell triggers immobility, then the ability of antidepressant drugs to block immobility may be related to their ability to block CREB activation in this region. Indeed, a variety of antidepressants block CREB phosphorylation in vitro (Schwaninger et al., 1995), and chronic antidepressants increase levels of cAMP phosphodiesterases, which metabolize cAMP and thereby decrease CREB activity, in the NAc shell (Takahashi et al., 1998). Antidepressants may be effective with short latencies in the FST because they interfere with early neuroadaptations induced by the initial exposure to forced swimming. These findings raise the possibility that agents that block CREB transcription in the NAc shell may have antidepressant efficacy. Although this may seem at odds with evidence that activation of CREB within the hippocampus regulates antidepressant efficacy (Duman et al., 1997), this difference underscores the fact that CREB would be expected to exert different behavioral effects depending on the type of neuron in question. Conceivably, these opposing requirements, CREB activation in the hippocampus and CREB inhibition in the NAc, may detract from the efficacy of antidepressants and cause delays in the onset of their therapeutic effects.

\section{Summary}

Considering that psychostimulants (Cole et al., 1995; Turgeon et al., 1997) and swim stress (the present studies) activate CREB in the NAc, CREB-regulated genes such as dynorphin may be involved in a variety of conditions associated with altered function of brain reward systems. Although other endogenous ligands have been implicated in affective disorders (Heim and Nemeroff, 1999), the present studies raise the possibility that elevated CREB expression in the NAc can trigger signs of dysphoria, and that viral-mediated elevations of CREB in the NAc could be used to facilitate the development of improved treatments for drug withdrawal or depression. 
Regardless, this work strengthens the hypothesized associations between upregulated cAMP systems in the NAc and drug withdrawal (Nestler, 2001) and other dysphoric states.

\section{REFERENCES}

Bals-Kubik R, Herz A, Shippenberg TS (1993) Evidence that the aversive effects of opioid antagonists and $\kappa$-agonists are centrally mediated. Psychopharmacology 98:203-206.

Carlezon Jr WA, Wise RA (1996) Rewarding actions of phencyclidine and related drugs in nucleus accumbens shell and frontal cortex. J Neurosci 16:3112-3122.

Carlezon Jr WA, Devine DP, Wise RA (1995) Habit-forming actions of nomifensine in nucleus accumbens. Psychopharmacology 122:194-197.

Carlezon Jr WA, Boundy VA, Haile CN, Lane SB, Kalb RG, Neve RL, Nestler EJ (1997) Sensitization to morphine induced by viralmediated gene transfer. Science 277:812-814.

Carlezon Jr WA, Thome J, Olson V, Lane-Ladd SB, Brodkin ES, Hiroi N, Duman RS, Neve RL, Nestler EJ (1998) Regulation of cocaine reward by CREB. Science 282:2272-2275.

Carlezon Jr WA, Haile CN, Coopersmith R, Hayashi Y, Malinow R, Neve RL, Nestler EJ (2000a) Distinct sites of opiate reward and aversion within the midbrain identified by a herpes simplex virus vector expressing GluR1. J Neurosci 20:RC62:1-5.

Carlezon Jr WA, Nestler EJ, Neve RL (2000b) Herpes simplex virusmediated gene transfer as a tool for neuropsychiatric research. Crit Rev Neurobiol 14:47-68.

Carr GD, Fibiger HC, Phillips AG (1989) Conditioned place preference as a measure of drug reward. In: The neuropharmacological basis of reward (Liebman JM, Cooper SJ, eds), pp 264-319. Oxford: Clarendon.

Chavkin C, James IF, Goldstein A (1982) Dynorphin is a specific endogenous ligand of the $\kappa$ opioid receptor. Science 215:413-415.

Cole RL, Konradi C, Douglass J, Hyman SE (1995) Neuronal adaptation to amphetamine and dopamine: molecular mechanisms of prodynorphin gene regulation in rat striatum. Neuron 14:813-823.

Daunais JB, Roberts DC, McGinty JF (1993) Cocaine selfadministration increases preprodynorphin, but not c-fos, mRNA in rat striatum. NeuroReport 4:543-546.

Detke MJ, Rickels M, Lucki I (1995) Active behaviors in the rat forced swimming test differentially produced by serotonergic and noradrenergic antidepressants. Psychopharmacology 121:66-72.

Di Chiara G, Imperato A (1988) Drugs of abuse preferentially stimulate dopamine release in the mesolimbic system of freely moving rats. Proc Natl Acad Sci USA 85:5274-5278.

Duman RS, Heninger GR, Nestler EJ (1997) A molecular and cellular theory of depression. Arch Gen Psychiatry 54:597-606.

Gawin FH, Kleber HD, Byck R, Rounsaville BJ, Kosten TR, Jatlow PI, Morgan C (1989) Desipramine facilitation of initial cocaine abstinence. Arch Gen Psychiatry 46:117-121.

Gonzalez GA, Montminy MR (1989) Cyclic AMP stimulates somatostatin gene transcription by phosphorylation of CREB at ser 133. Cell 59:675-680.

Heim C, Nemeroff CB (1999) The impact of early adverse experiences on brain systems involved in the pathophysiology of anxiety and affective disorders. Biol Psychiatry 46:1509-1522.

Hurd YL, Brown EE, Finlay JM, Fibiger HC, Gerfen CR (1992) Cocaine self-administration differentially alters mRNA expression of striatal peptides. Brain Res Mol Brain Res 13:165-170.

Jones DN, Holtzman SG (1992) Long term $\kappa$-opioid receptor blockade following nor-binaltorphimine. Eur J Pharmacol 215:345-348.
Kelz MB, Chen JS, Carlezon Jr WA, Whisler K, Gilden L, Steffen C, Zheng YJ, Marotti L, Self DW, Tkatch T, Baranauskas G, Surmeier DJ, Neve RL, Duman RS, Picciotto MR, Nestler EJ (1999) Expression of the transcription factor $\Delta$ FosB in the brain controls sensitivity to cocaine. Nature 401:272-276.

Koob GF, Le Moal M (2001) Drug addiction, dysregulation of reward, and allostasis. Neuropsychopharmacology 24:97-129.

Kreek MJ, Koob GF (1998) Drug dependence: stress and dysregulation of brain reward pathways. Drug Alcohol Depend 51:23-47.

Markou A, Hauger RL, Koob GF (1992) Desmethylimipramine attenuates cocaine withdrawal in rats. Psychopharmacology 109:305-314.

Nestler EJ (2001) Molecular basis of long-term plasticity underlying addiction. Nat Rev Neurosci 2:119-128.

Neve RL, Howe JR, Hong S, Kalb RG (1997) Introduction of the glutamate receptor subunit 1 into motor neurons in vitro and in vivo using recombinant herpes simplex virus. Neuroscience 79:435-447.

Paxinos G, Watson C (1997) The rat brain in stereotaxic coordinates, compact Ed 3. San Diego: Academic.

Pfeiffer A, Brantl V, Herz A, Emrich HM (1986) Psychotomimesis mediated by $\kappa$ opiate receptors. Science 233:774-776.

Porsolt RD, Le Pichon M, Jalfre M (1977) Depression: a new animal model sensitive to antidepressant treatments. Nature 266:730-732.

Rajadhyaksha A, Barczak A, Marcias W, Leveque JC, Lewis SE, Konradi C (1999) L-type $\mathrm{Ca}^{2+}$ channels are essential for glutamate-mediated CREB phosphorylation and c-fos gene expression in striatal neurons. J Neurosci 19:6348-6359.

Schwaninger M, Schofl C, Blume R, Rosswig L, Knepel W (1995) Inhibition by antidepressant drugs of cyclic AMP response element binding protein/cyclic AMP response element-directed gene transcription. Mol Pharmacol 47:1112-1118.

Self DW, Genova LM, Hope BT, Barnhardt WJ, Spencer JJ, Nestler EJ (1998) Involvement of cAMP-dependent kinase in the nucleus accumbens in cocaine self-administration and relapse of cocaine-seeking behavior. J Neurosci 18:1848-1859.

Shaywitz AJ, Greenberg ME (1999) CREB: a stimulus-induced transcription factor activated by a diverse array of extracellular signals. Annu Rev Biochem 68:821-861.

Shippenberg TS, Bals-Kubik R, Huber A, Herz A (1991) Neuroanatomical substrates mediating the aversive effects of D-1 dopamine receptor antagonists. Psychopharmacology 103:209-214.

Solomon RL, Corbit JD (1974) An opponent-process theory of motivation. I. Temporal dynamics of affect. Psychol Rev 81:119-145.

Spanagel R, Shippenberg TS (1993) Modulation of morphine-induced sensitization by endogenous $\kappa$ opioid systems in the rat. Neurosci Lett 153:232-236.

Spanagel R, Herz A, Shippenberg TS (1990) The effects of opioid peptides on dopamine release in the nucleus accumbens: an in vivo microdialysis study. J Neurochem 55:1734-1740.

Spangler R, Unterwald EM, Kreek MJ (1993) "Binge" cocaine administration induces a sustained increase of prodynorphin mRNA in rat caudate-putamen. Brain Res Mol Brain Res 19:323-327.

Takahashi M, Terwilliger R, Lane C, Menzes PS, Conti M, Duman RS (1998) Chronic antidepressant administration increases the expression of cAMP phosphodiesterase 4A and 4B isoforms. J Neurosci 19:610-618.

Turgeon SM, Pollack AE, Fink JS (1997) Enhanced CREB phosphorylation and changes in c-Fos and FR A expression in striatum accompany amphetamine sensitization. Brain Res 749:120-126.

Wise RA (1998) Drug-activation of brain reward pathways. Drug Alcohol Depend 51:13-22. 